\title{
STRUKTUR KOMUNITAS LARVA IKAN PADA SAAT PASANG SURUT DI MUARA SUNGAI MOROSARI SAYUNG, DEMAK
}

\author{
Community Structure of Fish Larvae during Tide and Low tide in the River Estuary of Morosari Sayung Village, Demak
}

\section{Prayogi Pahingguan, Bambang Sulardiono*), Wiwiet Teguh Taufani}

\author{
Program Studi Manajemen Sumberdaya Perairan, Departemen Sumberdaya Akuatik \\ Fakultas Perikanan dan Ilmu Kelautan, Universitas Diponegoro \\ Jl. Prof. Soedarto, SH, Tembalang, Semarang, Jawa Tengah - 50275, Telp/Fax. +6224 7474698 \\ Email :yogiismaill8@gmail.com
}

\begin{abstract}
ABSTRAK
Muara Sungai merupakan perairan semi tertutup yang terletak di bagian hilir sungai dan masih berhubungan dengan laut sehingga memungkinkan untuk terjadinya pencampuran dua massa air, yakni air tawar dan air laut. Tujuan penelitian untuk mengetahui komposisi dan kelimpahan larva ikan, mengetahui perbedaan struktur komunitas pada saat pasang dan surut. Metode yang di gunakan adalah metode survei yang dilaksanakan pada bulan Mei 2018 di Muara sungai Morosari Sayung, Demak. Sampling dilakukan pada 3 stasiun dengan kondisi pasang dan surut. Variabel yang diukur antara lain Komposisi, Kelimpahan Larva ikan dan Struktur komunitas pada saat pasang dan surut. Hasil penelitian didapatkan Larva ikan pada saat pasang di stasiun I sebanyak 43 ind, stasiun II diperoleh larva ikan sebanyak 22 ind dan stasiun III sebanyak 34 ind. Hasil penelitian didapatkan pada saat surut di stasiun I sebanyak 24 ind, stasiun II 22 ind dan stasiun III sebanyak 34 ind. Keseluruhan larva ikan yang tertangkap terdiri dari 10 famili yaitu Nemipteridae, Mugilidae, Gobiidae, Ambassidae, Acrididae, Chanidae, Engraulidae, Labridae, Scatophagidae dan Lactaridae. Indeks keanekaragaman pada saat pasang termasuk dalam kategori rendah dan sedang dengan nilai berkisar 0,99-1,6. Indeks keseragaman berkisar antara 0,78-0,91 maka tergolong kedalam kategori tinggi atau stabil. Nilai indeks Dominasi termasuk kedalam dominasi rendah dan sedang dengan nilai berkisar antara 0,22-0,40. Nilai indeks keanekaeragaman pada saat surut masuk dalam kategori rendah dan sedang dengan nilai berkisar 0,91-1,41. Indeks keseragaman berkisar 0,66-0,91 masuk dalam kategori stabil. Dominasi berkisar antara 0,32-0,45, dengan nilai tersebut maka dapat dikategorikan Dominasi sedang.
\end{abstract}

Kata Kunci: Kelimpahan, Struktur komunitas, Larva Ikan, Muara Sungai, Morosari

\begin{abstract}
Estuary is a semi-closed waters located in the downstream part of the river and still in contact with the sea, allowing for mixing of two water masses, namely fresh water and sea water. The purpose of this research is to find out the composition and abundance of fish larvae, to know the differences in community structure during high and low tide levels. The method used in this research is a survey method conducted in May 2018 in the river estuary of Morosari Sayung, Demak. Sampling was carried out at 3 tidal and low tide stations. Variables measured include Composition and Abundance of fish larvae and community structures during highs and low tide level. The research result showed that 43 ind larvae at high tide at station I, were 22 ind at stations II, were obtained and 34 ind stations III. The results of the research were obtained at low tide at station I as many as 24 ind, station II 22 ind and station III as many as 34 ind. All captured fish larvae consist of 10 families namely Nemipteridae, Mugilidae, Gobiidae, Ambassidae, Acrididae, Chanidae, Engraulidae, Labridae, Scatophagidae and Lactaridae. The diversity index value at the high tide entered in the low and medium category ranged from 0.99 to 1.6. Uniformity lindex ranges from 0.78 to 0.91 in the medium category. Domination ranges from 0.22 to 0.40 , with this value the entire research station into the category there is no dominance. The diversity index value at the low tide entered in the low and medium category ranged from 0.91 to 1.41 . The uniformity index ranges from 0.66 to 0.91 included in the stable category. Domination ranges from 0.32-0.45 with this value can be categorized medium.
\end{abstract}

Keywords: Abundance, Community Structure, Fish Larvae, Estuary, Morosari

*) Penulis Penanggungjawab

\section{PENDAHULUAN}

Sumberdaya larva ikan merupakan salah satu faktor utama dalam menentukan kelestarian sumberdaya hayati perikanan tawar dan perikanan laut. Stadia larva merupakan stadia yang penting bagi perkembangan, khususnya ikan. ketersediaan stadia larva ikan di alam menggambarkan keberadaan ikan dewasa. Larva yang merupakan fase awal dalam kehidupan ikan memiliki penyebaran yang berbeda-beda di setiap ekosistem. Kondisi suatu ekosistem perairan sangat menentukan kelimpahan dan distribusi organisme di dalamnya, namun setiap organisme memiliki kebutuhan yang berbeda untuk hidup sesuai dengan karakteristik kehidupannya Secara biologi fase larva akan banyak ditemui di 
daerah pesisir karena wilayah ini merupakan derah yang potensial untuk larva meneruskan pertumbuhannya, selain karena adanya naluri dari induk ketika memijah, juga dipengaruhi oleh ketersediaan makanan dan ruang. Perairan pantai yang terdiri dari daerah pasang surut, estuari, mangrove, padang lamun, terumbu karang, maupun pantai berpasir merupakan nursery bagi berbagai jenis ikan. Melalui mekanisme hidro-biologi larva ikan yang dilahirkan di daerah lepas pantai akan menuju daerah habitat nursery yang kemudian keberhasilan hidupnya akan berpengaruh terhadap rekrutmen (Amarullah, 2008).

Muara Sungai merupakan perairan semi tertutup yang terletak di bagian hilir sungai dan masih berhubungan dengan laut sehingga memungkinkan untuk terjadinya pencampuran dua massa air, yakni air tawar dan air laut (Dahuri et al., 2001).

Menurut Nomura dan Yamazaki (1977) alasan utama sebagian spesies ikan berkumpul pada suatu wilayah perairan disebabkan beberapa hal :

1. Ikan akan memilih lingkungan hidupnya yang sesuai dengan kondisi tubuhnya

2. Mencari sumber makanan yang banyak

3. Mencari tampat yang cocok untuk pemijahan dan perkembangbiakan

Berdasarkan hal tersebut terdapat pembatasan penyebaran yang menunjukkan bahwa pola sebaran ikan sangat ditentukan atau dipengaruhi oleh kondisi lingkungan dimana sumberdaya ikan tersebut berada. Jika suatu kawasan tempat ikan melangsungkan hidupnya rusak, maka hanya sedikit ikan yang datang, bahkan mungkin tidak ada sama sekali. Melihat pentingnya ekosistem mangrove di pesisir Desa Morosari, Demak, maka tempat ini dipilih sebagai lokasi sampling, karna daerah ini memiliki potensi sebagai daerah pemijahan ikan (spawning ground).

Tujuan dari kegiatan penilitian ini adalah:

1. Mengetahui komposisi larva ikan pada saat pasang dan surut dimuara sungai morosari, Demak.

2. mengetahui perbedaan struktur komunitas pada saat pasang surut dimuara sungai morosari, Demak

\section{MATERI DAN METODE PENELITIAN}

Materi yang digunakan dalam penelitian ini adalah sampel larva ikan yang diambil dari peraian muara sungai Dusun Morosari, Kecamatan Sayung, Kabupaten Demak. Selain itu dilakukan pengukuran kualitas peraian meliputi suhu, kecepatan arus, $\mathrm{pH}$ dan salinitas.

Metode yang digunakan dalam penelitian ini adalah metode survei. Metode survei adalah metode penelitian yang dilakukan untuk memperoleh fakta-fakta dari gejala-gejala yang ada serta mencari keterangan-keterangan secara faktual. Metode survei ini dilakukan terhadap sekumpulan obyek dengan asumsi bahwa obyek yang diteliti telah mewakili populasi yang diamati (Nazir, 1988)

Sampel larva ikan diambil dari lokasi penelitian dengan cara memasang seine net dengan panjang $2 \mathrm{~m}$, lebar $1 \mathrm{~m}$ dan ukuran mata jaring $1 \mathrm{~mm}$. Seine net tersebut dioperasikan dengan cara di dorong dengan jarak kurang lebih 50 meter . Sampel larva ikan yang tertangkap selanjutnya dimasukkan ke botol yang telah berisi formalin 4\%) dan dibawa ke laboratorium untuk dilakukan identifikasi .

Lokasi Penilitian dilakukan pada 3 stasiun pada saat pasang dam surut di muara sungai Morosari Semarang degan 2 kali pengulangan dapat dilihat pada Gambar 4.

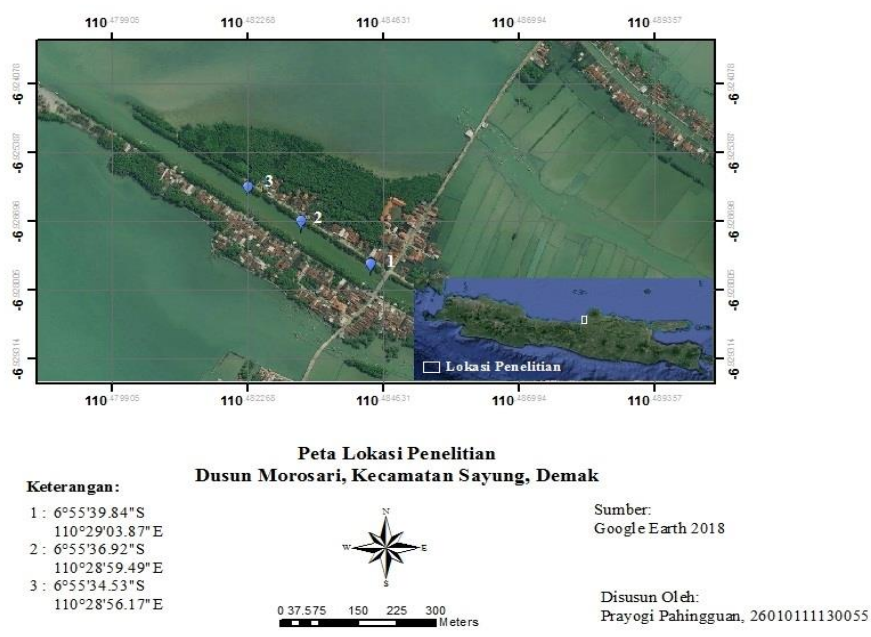

Gambar 4. Peta Stasiun Penilitian

\section{Analisis Data}

Semua data yang terkumpul akan dianalisis adapun analisis data dilakukan secara deskriptif. Analisis jenis ini hanya dapat digunakan untuk mendapatkan gambaran umum mengenai sebaran data. Menurut Hadi (1982), analisis deksriptif digunakan untuk dapat menggambarkan mengenai situasi dan kondisi pada waktu dan tempat yang terbatas 
untuk mengetahui situasi dan kondisi lokal suatu lokasi yang dapat digeneralisasikan pada waktu dan lokasi yang berbeda.

\section{Kelimpahan Larva Ikan}

Kelimpahan larva ikan yang didefinisikan sebagai banyaknya larva ikan persatuan volume air dihitung dengan menggunakan rumus :

$$
\mathrm{N}=\mathrm{n} / \mathrm{V}_{\text {tsr }}
$$

Dimana :

$$
\begin{aligned}
& \mathrm{N}=\text { kelimpahan larva ikan }\left(\mathrm{ind} / \mathrm{m}^{3}\right) \\
& \mathrm{n}=\text { jumlah larva tercacah }(\mathrm{ind}) \\
& \mathrm{Vtsr} \text { = volume air tersaring }(\mathrm{Vtsr}=\mathrm{p} \times 1 \times \mathrm{v}) \\
& \mathrm{p}=\text { panjang Seine } \text { net }(\mathrm{m}) \\
& \mathrm{l}=\text { lebar seine net }(\mathrm{m}) \\
& \mathrm{t}=\text { Jarak sapuan seine } \text { net }(\mathrm{m})
\end{aligned}
$$

\section{Indeks Keanekaragaman Larva Ikan}

Indeks keanekaragaman larva diperlukan untuk menggambarkan kehadiran jumlah individu antar genus dalam suatu komunitas. Nilai ini dihitung dengan menggunakan indeks Shannon-Wiener (Bengen, 2000). Formulasi Indeks Keanekaragaman Shannon-Wiener berdasarkan persamaan sebagai berikut :

Keterangan :

$$
H^{\prime}=-\sum_{i=1}^{s} \text { pi } \ln p i
$$

$\mathrm{H}^{\prime}=$ Indeks Keanekaragaman

$\mathrm{N}=$ jumlah total individu dalam komunitas (ni)

$\mathrm{ni}=$ jumlah individu spesies atau jenis ke-i

$\mathrm{pi}=$ proporsi individu spesies $\mathrm{ke}-\mathrm{i}(\mathrm{ni} / \mathrm{N})$

$\mathrm{i}=1,2,3, \ldots . ., \mathrm{s}$

$\mathrm{s}=$ jumlah genus/spesies

Kriteria nilai indeks keanekaragaman Shannon - Wiener $\left(H^{\prime}\right)$ adalah sebagai berikut:

$\mathrm{H}^{\prime}<1 \quad$ : keanekaragaman rendah

$1<\mathrm{H}<3 \quad$ : keanekaragaman sedang

H’>3 : keanekaragaman tinggi

\section{Indeks Keseragaman Larva Ikan}

Keseragaman adalah suatu gambaran tentang sebaran individu dari setiap spesies dalam suatu komunitas. Nilai indeks keseragaman (E) dihitung berdasarkan persamaan berikut :

$$
E=\frac{H^{\prime}}{H^{\prime} m a k s} \text { atau } E=\frac{H^{\prime}}{\ln s}
$$

Keterangan :

$\mathrm{E}=$ indeks keseragaman

$\mathrm{H}^{\prime}=$ indeks keanekaragaman

$\mathrm{s}=$ jumlah genus/spesies

Indeks Keseragaman (E) digunakan untuk mengetahui seberapa besar kesamaan penyebaran jumlah individu dari setiap genus/spesies pada tingkat komunitas. Nilai indeks keseragaman berkisar antara 0-1. Nilai E mendekati 1 apabila sebaran individu antar jenis merata (seragam) sedangkan Nilai E mendekati 0 apabila sebaran individu tidak merata atau ada jenis yang mendominasi. Selanjutnya nilai indeks keseragaman berdasarkan Kreb (1972)

dikategorikan sebagai berikut :

$0<\mathrm{E} \leq 0.5 \quad$ : Rendah atau komunitas tertekan

$0.5<\mathrm{E} \leq 0.75 \quad$ : Sedang atau komunitas labil

$0.75<\mathrm{E} \leq 1 \quad$ : Tinggi atau Komunitas stabil 


\section{Indeks Dominasi}

Untuk melihat dominansi suatu jenis digunakan indeks dominansi Simpson (Odum, 1971) sebagai berikut:

$$
D=\sum_{i=l}^{S}(P i)^{2}
$$

Dimana :

$$
P i=n i / N
$$

$n i=$ jumlah individu dari jenis ke-i

$N=$ jumlah total individu

$\mathrm{Pi}=$ proporsi individu jenis ke-i

Menurut Dhahiyat et al. (2009) kisaran indeks dominansi adalah sebagai berikut :

$0,00 \leq \mathrm{D} \leq 0,30$ : Dominansi rendah

$0,30 \leq \mathrm{D} \leq 0,60$ : Dominansi sedang

$0,60 \leq \mathrm{D} \leq 1.00$ : Dominansi tinggi

\section{HASIL DAN PEMBAHASAN}

\section{Gambaran Umum Lokasi Penelitian}

Demak adalah salah satu kabupaten di jawa tengah terletak pada 6043'26" sampai $7^{\circ} 09^{\prime} 43^{\prime \prime}$ Lintang Selatan dan $110^{\circ} 48^{\prime} 47^{\prime \prime}$ Bujur timur. Sebelah Utara berbatasan dengan Kabupaten Jepara dan Laut Jawa, Sebelah Timur berbatasan dengan Kabupaten Kudus dan Kabupaten Grobogan. Sebelah Selatan berbatasan dengan Kabupaten Grobogan dan Kabupaten Semarang, dan sebelah Barat berbatasan dengan Kota Semarang.

Kondisi perairan pesisir di Demak khususnya di Muara Sungai Morosari Sayung. Muara Sungai Morosari berada di Kecamatan Sayung, Kabupaten Demak. Perairan ini digunakan untuk pembuangan limbah domestik maupun industri, jalur lalu lintas perahu nelayan, kawasan wisata, dan kegiatan perikanan. Hal ini diduga mempengaruhi kualitas perairan..

\section{Kondisi Kualitas Perairan Pada Saat Pasang}

Parameter yang digunakan pada saat smapling di lapangan dan sebagai parameter kualitas air meliputi suhu air, $\mathrm{PH}$, salanitas, DO, kedalaman, kecepatan arus. Adapun hasil pengukuran dari 3 stasiun penilitian dapat dilihat pada tabel 1 .

Tabel 1. Data kisaran Parameter Kualitas Air Pada Saat Pasang di Tiga Lokasi

\begin{tabular}{ccccccccc}
\hline Minggu & Stasiun & $\begin{array}{c}\text { Kedalaman } \\
(\mathrm{cm})\end{array}$ & $\begin{array}{c}\text { Kecerahan } \\
(\mathrm{cm})\end{array}$ & $\begin{array}{c}\text { Arus } \\
(\mathrm{m} / \mathrm{s})\end{array}$ & $\begin{array}{c}\text { Salinitas } \\
(\%)\end{array}$ & $\mathrm{pH}$ & DO $(\mathrm{mg} / \mathrm{l})$ & $\begin{array}{c}\text { Suhu } \\
\left({ }^{\circ} \mathrm{C}\right)\end{array}$ \\
\hline \multirow{3}{*}{1} & 1 & $103-112$ & $8-10$ & $\begin{array}{c}0,06- \\
0,11\end{array}$ & 28 & 7 & $4,78-4,62$ & 30 \\
& 2 & $90-128$ & $15-28,5$ & $0,05-0,1$ & 29 & 7 & $4,46-5,21$ & 31 \\
& 3 & $101-150$ & 28,5 & $\begin{array}{c}0,08- \\
0,12\end{array}$ & 30 & 7 & $4,34-5,25$ & 33 \\
\hline & 1 & $103-112$ & $17-23,5$ & $\begin{array}{c}0,05- \\
0,12\end{array}$ & 28 & 7 & $4-5,23$ & 31 \\
& 2 & $95-132$ & $8-18$ & $0,05-0,1$ & 29 & 8 & $4,4-4,5$ & 31 \\
& 3 & $102-131$ & $8-15$ & $0,06-$ & 30 & 8 & $4,5-4,6$ & 30 \\
\hline
\end{tabular}

a. Suhu air

Suhu air yang diperoleh minggu pertama memiliki kisaran $30-33{ }^{\circ} \mathrm{C}$ dikarnakan pengukuran dilakukan pada siang hari. Suhu air yang diperoleh pada minggu ke-2, stasiun 1 dan 2 memiliki nilai yang sama yaitu 31 dan terjadi penurunan suhu pada stasiun 3 dikarnakan Pengukuran suhu dilakukan pada sore hari

b. Kedalaman dan kecerahan

Kedalaman dan kecerahan sangat berkaitan dengan suhu. Nilai kedalaman pada minggu pertama stasiun 3 adalah yang tertinggi dilihat dari kisaran $101-150 \mathrm{~cm}$. kecerahan paling tinggi yaitu pada stasiun 2 dan 3 dengan kisaran $15-28,5 \mathrm{~cm}$. 
c.

Arus

Nilai arus yang terdapat pada 3 stasiun dengan 2 kali pengulangan interval waktu 1 minggu antara lain. Nilai arus pada minggu pertama stasiun 3 adalah yang tertinggi dilihat dari kisaran $0,08-0,12 \mathrm{~m} / \mathrm{s}$. Arus paling tinggi pada minggu ke-2 yaitu pada stasiun 1 dengan kisaran $0,05-0,12 \mathrm{~m} / \mathrm{s}$

d. Salanitas

Salinitas tertinggi pada minggu ke-1 dan ke-2 adalah 30 yang terdapat pada stasiun 3 , hal ini disebabkan karena lokasi stasiun 3 yang paling dekat dengan air laut, sehingga campuran air laut lebih tinggi dibanding stasiun yang lain.

e. $\mathrm{pH}$

pH dalam perairan dapat mempengaruhi ketersediaan unsur-unsur kimia dan hara yang sangat bermanfaat bagi kehidupan vegetasi akuatik. Nilai $\mathrm{pH}$ dari ke 3 stasiun mingu ke-1 dan ke-2 sekitar $7-8$, nilai $\mathrm{pH}$ tersebut termasuk $\mathrm{pH}$ optimal untuk perairan payau .

f. DO

Nilai DO tertinggi pada minggu ke-1 terdapat pada stasiun 3 yaitu 4,34-5,25 mg/l, dan nilai DO tertinggi pada minggu ke-2 terdapat pada stasiun 1 yaitu 4-5,23 hal ini disebabkan karena pada saat pengukuran DO di stasiun 3 dan 1 dilakukan pada siang hari, sehingga memacu proses fotosintesis bagi fitoplankton yang menghasilkan banyak oksigen.

\section{Kondisi Kualitas Perairan Pada Saat Surut}

Parameter yang digunakan pada saat smapling di lapangan dan sebagai parameter kualitas air meliputi suhu air, PH, salanitas, DO, kedalaman, kecepatan arus. Adapun hasil pengukuran dari 3 stasiun penilitian dapat dilihat pada tabel 2.

Tabel 1. Data kisaran Parameter Kualitas Air Pada Saat Surut di Tiga Lokasi

\begin{tabular}{ccccccccc}
\hline Minggu & Stasiun & $\begin{array}{c}\text { Kedalaman } \\
(\mathrm{cm})\end{array}$ & $\begin{array}{c}\text { Kecerahan } \\
(\mathrm{cm})\end{array}$ & $\begin{array}{c}\text { Arus } \\
(\mathrm{m} / \mathrm{s})\end{array}$ & $\begin{array}{c}\text { Salinitas } \\
(\%)\end{array}$ & $\mathrm{pH}$ & DO $(\mathrm{mg} / \mathrm{l})$ & $\begin{array}{c}\text { Suhu } \\
\left({ }^{\circ} \mathrm{C}\right)\end{array}$ \\
\hline \multirow{2}{*}{1} & 1 & $90-104$ & $\infty$ & $0,11-0,14$ & 27 & 7 & $4,78-5$ & 30 \\
& 2 & $94-115$ & $\infty$ & $0,09-0,16$ & 29 & 7 & $3,60-4,93$ & 29 \\
\hline & 3 & $89-103$ & $\infty$ & $0,1-0,14$ & 30 & 7 & $4,24-4,53$ & 29 \\
\hline & 1 & $90-103$ & $\infty$ & $0,06-0,2$ & 27 & 7 & $3,9-4,1$ & 28 \\
& 2 & $96-116$ & $\infty$ & $0,1-0,2$ & 29 & 7 & $4,0-4,8$ & 27 \\
\hline
\end{tabular}

a. Suhu air

Suhu air yang diperoleh minggu pertama memiliki kisaran $29-30{ }^{\circ} \mathrm{C}$. Suhu air pada stasiun 1 yaitu $30{ }^{\circ} \mathrm{C}$ dan terjadi penurunan suhu pada stasiun 2 dengan suhu $29{ }^{\circ} \mathrm{C}$, dikarnakan pengukuran dilakukan pada sore hari. Suhu air yang diperoleh pada minggu ke-2 memiliki kisaran $27-28{ }^{\circ} \mathrm{C}$. Suhu air pada stasiun 1 yaitu $28^{\circ} \mathrm{C}$ dan terjadi penurunan suhu pada stasiun 2 dengan suhu $27^{\circ} \mathrm{C}$ dikarnakan Pengukuran suhu dilakukan pada malam hari.

b. Kedalaman dan kecerahan

Kedalaman sangat berkaitan dengan suhu. Nilai kedalaman minggu kedua pada stasiun 2 adalah yang tertinggi dilihat dari kisarannya yaitu $96-116 \mathrm{~cm}$

c. Arus

Nilai kecepatan arus minggu kedua pada stasiun 3 adalah yang tertinggi dilihat dari kisarannya yaitu 0,12-0,2 $\mathrm{m} / \mathrm{s}$.

d. Salanitas

Salinitas tertinggi yaitu pada minggu ke-1 adalah 30 yang terdapat pada stasiun III, hal ini disebabkan karena lokasi stasiun 3 yang paling dekat dengan air laut, sehingga campuran air laut lebih tinggi dibanding stasiun yang lain. e. $\mathrm{pH}$

pH dalam perairan dapat mempengaruhi ketersediaan unsur-unsur kimia dan hara yang sangat bermanfaat bagi kehidupan vegetasi akuatik. Nilai $\mathrm{pH}$ dari ke 3 stasiun mingu ke-1 dan ke-2 sekitar $7-8$, nilai $\mathrm{pH}$ tersebut termasuk $\mathrm{pH}$ optimal untuk perairan payau .

f. DO

Nilai DO tertinggi pada minggu ke-1 terdapat pada stasiun 3 yaitu 4,78-5 mg/l, dan nilai DO tertinggi pada minggu ke-2 terdapat pada stasiun 2 yaitu 4,0-4,8. 


\section{Komposisi Larva Ikan}

Jumlah total larva ikan selama dua kali sampling pada saat pasang di muara sungai morosari adalah stasiun I sebanyak 43 individu, stasiun II diperoleh larva sebanyak 22 individu dan di stasiun III diperoleh sebanyak 34 individu. Jumlah total larva ikan selama dua kali sampling pada saat surut di muara sungai morosari adalah stasiun I sebanyak 24 individu, di stasiun II diperoleh larva ikan sebanyak 21 individu dan di stasiun III diperoleh sebanyak 33 individu. Keseluruhan larva ikan yang tertangkap terdiri dari 10 famili yaitu Nemipteridae, Mugilidae, Gobiidae, Ambassidae, Acrididae, Chanidae, Engraulidae, Labridae, Scatophagidae dan Lactaridae. Komposisi jenis dan jumlah total larva ikan ditiga stasiun pada saat pasang dan surut dapat dilihat pada Tabel 3 dan 4.

Tabel 3. Komposisi jenis dan jumlah individu larva ikan yang tertangkap selama penilitian pada saat pasang

\begin{tabular}{clccc}
\hline \multirow{2}{*}{ No } & \multirow{2}{*}{ Familli } & \multicolumn{3}{c}{ Lokasi sampling } \\
\cline { 3 - 5 } & Nemipteridae & 22 & I & III \\
\hline 1 & Mugilidae & 13 & 6 & 11 \\
2 & Gobiidae & 7 & 4 & 6 \\
3 & Ambassidae & 1 & 0 & 8 \\
4 & Acrididae & 0 & 0 & 0 \\
5 & Chanidae & 0 & 0 & 1 \\
6 & Engraulidae & 0 & 0 & 1 \\
7 & Labridae & 0 & 0 & 5 \\
8 & Jumlah & 43 & 22 & 34
\end{tabular}

Sumber : Hasil penilitian Mei 2018

Tabel 3 memperlihatkan bahwa familli Nemipetridae paling banyak ditemukan disetiap stasiun sampling dan diikuti oleh famili Mugilidae. Selama penilitian, terdapat tiga famili yang paling sedikit ditemukan selama penilitian yaitu dari faimili Acrididae, Ambassidae dan Engraulidae.

Tabel 4. Komposisi jenis dan jumlah individu larva ikan yang tertangkap selama penilitian pada saat surut

\begin{tabular}{llccc}
\hline \multirow{2}{*}{ No } & \multirow{2}{*}{ Familli } & I & Lokasi sampling & III \\
\cline { 3 - 5 } & & 12 & 3 & 18 \\
1 & Nemipteridae & 1 & 0 & 0 \\
2 & Mugilidae & 3 & 0 & 13 \\
3 & Gobiidae & 5 & 9 & 1 \\
4 & Ambassidae & 1 & 9 & 0 \\
5 & Scatophagidae & 0 & 0 & 1 \\
6 & Engraulidae & 2 & 0 & 0 \\
7 & lactaridae & 24 & 21 & 33 \\
\hline
\end{tabular}

Sumber : Hasil penilitian Mei 2018

Tabel 4 memperlihatkan bahwa familli Nemipetridae paling banyak ditemukan disetiap stasiun sampling dan diikuti oleh famili Gobiidae. Selama penilitian, terdapat satu famili yang paling sedikit ditemukan selama penilitian yaitu dari faimili Engraulidae pada stasiun III

\section{Kelimpahan larva Ikan}

Dengan asumsi bahwa volume air yang tersaring dengan seine Net adalah sama, maka perhitungan kelimpahan Larva ikan pada saat pengambilan sampel pasang dan surut di tiga stasiun dapat dilihat pada tabel 5 dan 6 .

Tabel 5. Rata-rata Kelimpahan Larva Ikan pada saat pasang (Ind/ $\left.\mathrm{m}^{3}\right)$ pada tiga stasiun pengambilan sampel

\begin{tabular}{lll}
\hline Lokasi & $\mathrm{n}(\mathrm{ind})$ & $\mathrm{N}\left(\mathrm{Ind} / \mathrm{m}^{3}\right)$ \\
\hline Stasiun I & 43 & 0,215 \\
Stasiun II & 22 & 0,110 \\
Stasiun III & 34 & 0,113 \\
\hline
\end{tabular}

Sumber : Hasil Penilitian Mei 2018

Keterangan $\mathrm{n}=$ jumlah individu larva ikan, $\mathrm{N}=$ kelimpahan larva ikan (Ind/ $\mathrm{m}^{3}$ )

Kelimpahan rata-rata di tiga stasiun penilitian menunjukkan bahwa pada stasiun I memiliki kelimpahan yang paling tinggi diikuti stasiun III dan yang paling rendah adalah stasiun

Tabel 6. Rata-rata Kelimpahan Larva Ikan pada saat surut (Ind/ $\mathrm{m}^{3}$ ) pada tiga stasiun pengambilan sampel

\begin{tabular}{lll}
\hline Lokasi & $\mathrm{n}$ (ind) & $\mathrm{N}\left(\mathrm{Ind} / \mathrm{m}^{3}\right)$ \\
\hline Stasiun I & 24 & 0,120 \\
Stasiun II & 21 & 0,105 \\
\hline
\end{tabular}




\begin{tabular}{ccc}
\hline Stasiun III & 33 & 0,165 \\
\hline
\end{tabular}

Sumber : Hasil Penilitian Mei 2018

Keterangan $\mathrm{n}=$ jumlah individu larva ikan, $\mathrm{N}=$ kelimpahan larva ikan (Ind/ $\mathrm{m}^{3}$ )

Kelimpahan rata-rata di tiga stasiun penilitian menunjukkan bahwa pada stasiun III memiliki kelimpahan yang paling tinggi diikuti stasiun I dan yang paling rendah adalah stasiun

\section{Struktur Komunitas Larva Ikan}

Hasil perhitungan Indeks Keanekaragaman (H'), Indeks Keseragaman (e) dan Indeks Dominasi (D). dapat dilihat pada tabel 8 dan 9 .

Tabel 7. Indeks keanekaragaman, Indeks Keseragaman, dan Indeks Dominasi pada saat Pasang dari Tiga Stasiun Penilitian

\begin{tabular}{lllll}
\hline No & Lokasi & H' & E & D \\
\hline 1 & Stasiun I & 1,09 & 0,78 & 0,38 \\
2 & Stasiun II & 0,99 & 0,91 & 0,40 \\
3 & Stasiun III & 1,67 & 0,86 & 0,22 \\
\hline
\end{tabular}

Sumber : Hasil Penilitian Mei 2018

Tabel 9. Indeks keanekaragaman, Indeks Keseragaman, dan Indeks Dominasi pada saat Surut dari Tiga Stasiun Penilitian

\begin{tabular}{lllll}
\hline No & Lokasi & H' & E & D \\
\hline 1 & Stasiun I & 1,41 & 0,78 & 0,32 \\
2 & Stasiun II & 1,00 & 0,391 & 0,39 \\
3 & Stasiun III & 0,91 & 0,66 & 0,44 \\
\hline
\end{tabular}

Sumber : Hasil Penilitian Mei 2018

\section{Pembahasan}

\section{Komposisi Larva Ikan}

Larva ikan yang didapatkan dari 3 stasiun di muara sungai Morosari, Demak terdiri dari 10 famili ikan. Famili ikan yang tertangkap antara lain Nemipetridae, Gobbidae, Mugilidae, Creediidae, Chanidae, Engraulidae, Labridae, Scatophagidae, Lactaridae. Nemi petridae merupakan famili ikan yang paling banyak ditemukan di Muara Sungai Morosari selama penilitian. Ikan ini paling banyak ditemukan di stasiun I pada saat pasang., kemungkinan besar pada saat penilitian merupakan musim pemijahan. Hal ini diperkuat oleh penilitian yang dilakukan oleh Riniatsih (2016), bahwa famili yang ditemukan selama penelitian diantaranya adalah famili Gobiidae, Apogonidae, dan Lutjanidae. Namun jika penelitian Riniatsih (2016) dibandingkan dengan penelitian yang telah dilakukan, kelimpahan tertinggi diperoleh dari famili Gobiidae karena dimungkinkan saat waktu sampling bertepatan dengan waktu pemijahan ikan dari famili Gobiidae.

Famili Nemipteridae ditemukan pada setiap sampling dan jumlahnya banyak ditemukan di daerah mangrove dengan kerapatan padat. Nemipteridae ditemukan di perairan pesisir pantai dengan substrat lumpur dan pasir serta perairan lepas pantai dengan berbagai kedalaman. Umumnya ikan jenis ini banyak ditemukan di perairan dangkal. FAO (2001), Nemipteridae dapat hidup secara soliter dan berkelompok (schooling). Ikan jenis ini merupakan ikan karnivora dengan makanan utamanya adalah ikan kecil lainnya, cumi-cumi, udang, dan polychaeta. Nemipteridae menunjukkan perbedaan ukuran yang berhubungan dengan rasio jenis kelamin yaitu individu betina lebih kecil dan individu jantan lebih besar. Musim pemijahan ikan jenis ini bervariasi dari masing-masing spesiesnya (Ramadhian, 2016)

Hasil penilitian juga menunjukkan bahwa lokasi penilitian pada stasiun I, II dan III didominasi oleh larva ikan dari famili Gobbidae dan Mugilidae. Gobbidae juga merupakan jenis ikan yang sering ditemukan di ketiga stasiun pada saat pasang. Hal ini dikarnakan penyebaran famili gobbidae sangat luas, dan memiliki toleransi atau kemampuan adaptasi yang baik terhadap perubahan salinitas yang besar. Larva Gobbidae memiliki kemampuan adaptasi yang baik terhadap lingkungan eustuari dan biasanya dominan tertangkap diperairan tersebut disamping itu pengambilan sampel bertepatan dengan waktu pemijahan yaitu bulan Mei-November (Ruswanda, 2015)

Komposisi dan kelimpahan larva dan juvenil ikan di setiap stasiun berbeda-beda. Hal ini disebabkan oleh tiga hal, yakni waktu sampling, vegetasi dan kondisi fisik perairan (arus dan pasang surut). Waktu sampling larva yang terbagi menjadi 3 periode yakni, siang, sore dan malam hal ini memiliki hubungan terhadap pasang surut dan kedalaman perairan. Ketika pasang, aliran masuk dari air laut banyak masuk ke dalam muara sehingga menyebabkan salinitas perairan cukup tinggi. Vegetasi mangrove di sekitar lokasi penelitian juga berperan dalam tingkat produktivitas primer di perairan. Pengambilan sampel di masing-masing stasiun dilakukan pada waktu yang berbeda pada saat passang $(10.00-12.00,14.00-16.00)$ dan pada saat surut $(18.00-20.00,21.00-23.00)$ di setiap stasiun. Hal ini memungkinkan terjadinya kelimpahan larva meningkat di waktu tertentu. Pukul $10.00-12.00$ merupakan waktu terbaik, cahaya matahari yang terserap di perairan digunakan oleh fitoplankton untuk melakukan fotosintesis sehingga menghasilkan makanan dan oksigen terlarut di perairan. Semakin tinggi kadar oksigen terlarut di perairan berhubungan dengan tingkat kelangsungan hidup larva ikan di perairan, begitu pula dengan makanan yang tersedia di perairan. 
Komposisi dan kelimpahan larva ikan terbesar pada saat pasang terdapat di stasiun 1 sebesar 0,2 ind/ $\mathrm{m}^{3}$. Penangkapan larva ikan di stasiun 1 dilakukan pada siang jari hari dengan kondisi perairan yang cukup baik, yakni nilai suhu air, DO, salinitas dan arus perairan masing-masing adalah $30^{\circ} \mathrm{C} ; 4,78 ; 27 \%$; dan $0,06-0,11 \mathrm{~m} /$ det. Komposisi dan kelimpahan larva ikan pada saat surut terdapat pada stasiun 3 sebesar 0,16 ind/ $\mathrm{m}^{3}$. Penangkapan larva ikan di stasiun 3 dilakukan pada malam hari dengan kondisi perairan yang cukup baik, yakni nilai suhu air, DO, salinitas dan arus perairan masingmasing adalah $27^{\circ} \mathrm{C} ; 4,6 ; 29 \%$; dan $0,12-0,2 \mathrm{~m} /$ det.

\section{Struktur Komunitas}

Nilai indeks keanekaragaman larva ikan pada saat pasang di Muara Sungai Morosari Sayung Demak dengan nilai tertinggi didapatkan di stasiun III dengan nilai $(1,67)$, selanjutnya adalah stasiun I dengan nilai (1.09) dan terendah di stasiun II $(0,99)$. Hal ini menunjukkan bahwa keanekaragaman individu larva ikan sedang, dengan kesetabilan komunitas larva ikan sedang. Nilai indeks keanekaragaman larva ikan pada saat surut di Muara Sungai Morosari Sayung Demak dengan nilai tertinggi didapatkan di stasiun I dengan nilai $(1,41)$, selanjutnya adalah stasiun II dengan nilai $(1,00)$ dan terendah di stasiun III $(0,91)$. Hal ini menunjukkan bahwa keanekaragaman individu larva ikan sedang, dengan kesetabilan komunitas larva ikan sedang. Krebs dalam Suprapto (2014) komunitas di perairan ini berada dalam kategori keragaman "sedang", karena nilai H' berada pada kisaran antara 1-3. Hal ini tidak menutup kemungkinan karna adanya pengaruh arus pasang dan terdapat mangrove sebagai habitat.

Indeks Keseragaman (E) digunakan untuk mengetahui seberapa besar kesamaan penyebaran jumlah induvidu setiap genus pada tingkat komunitas disetiap lokasi penelitian (Odum,1971). Hasil analisis menunjukkan bahwa nilai indeks keseragaman pada saat pasang disetiap stasiun memiliki nilai yaitu di stasiun I $(0,78)$ stasiun II $(0,91)$ dan stasiun III (0,86). Menurut kriteria Bahara (2009), bahwa nilai indeks keseragaman pengamatan dibagi menjadi pada kriteria sedang atau labil dan tinggi atau stabil. Kriteria pertama dengan nilai $0,50 \leq \mathrm{E} \leq 0,75$. yaitu ekosistem labil. Sedangkan kriteria kedua yaitu dengan nilai indeks keseragaman $0,75 \leq \mathrm{E} \leq 1,00$ yaitu ekosistem stabil. indeks keseragaman dengan kriteria yang pertama masuk dalam lokasi penelitain, sehingga dengan demikian pada stasiun I, II dan stasiun III masuk dalam katagori stabil. Indeks keseragaman pada saat surut disetiap stasiun memiliki nilai yaitu di stasiun I $(0,78)$ stasiun II $(0,91)$ dan stasiun III $(0,66)$. Indeks keseragaman dengan kriteria yang pertama masuk dalam ketiga lokasi penelitain, sehingga dengan demikian indeks keseragaman pada saat surut masuk dalam kategori stabil.

Hasil analisis indeks dominasi pada saat pasang antar stasiun diperoleh indeks dominasi di stasiun I $(0,38)$ stasiun II $(0,40)$ dan di stasiun III $(0,22)$ dengan indeks dominasi maka dapat disimpulkan dari ketiga stasiun tersebut hanya stasiun III dalam kategori dominasi rendah sedangkan pada stasiun I dan II termasuk kategori dominan sedang. Hasil analisis indeks dominasi pada saat surut antar stasiun diperoleh indeks dominasi di stasiun I $(0,32)$ stasiun II $(0,39)$ dan di stasiun III $(0,45)$, artinya ketiga stasiun tersebut tergolong dalam kategori Dominasi sedang. Krebs (1985) dalam Wizuri et al., ( 2012), Menyatakan bahwa penghilang satu spesies dominan dalam suatu komunitas sering kali terjadi karna pengaruh manusia terhadap komunitas . Basmi (2000) menmbahkan bila dalam suatu struktur komunitas biota yang di amati terdapat spesies yang mendominasi, maka hal ini menunjukkan bahwa kondisi struktur komunitas berada pada keadaan labil atau sedang terjadi tekanan ekologis. Sedangkan yang terjadi pada saat penilitian berbanding terbalik yaitu tidak ada yang mendominasi.

\section{KESIMPULAN}

Kesimpulan yang diperoleh dari penilitian ini adalah sebagai berikut:

Jumlah total larva ikan selama dua kali sampling pada saat pasang di muara sungai morosari adalah stasiun I sebanyak 43 individu, stasiun II diperoleh larva sebanyak 22 individu dan di stasiun III diperoleh sebanyak 34 individu. Jumlah total larva ikan selama dua kali sampling pada saat surut di muara sungai morosari adalah stasiun I sebanyak 24 individu, di stasiun II diperoleh larva ikan sebanyak 21 individu dan di stasiun III diperoleh sebanyak 33 individu. Keseluruhan larva ikan yang tertangkap terdiri dari 10 famili yaitu Nemipteridae, Mugilidae, Gobiidae, Ambassidae, Acrididae, Chanidae, Engraulidae, Labridae, Scatophagidae, Lactaridae.

Nilai indeks keanekaragaman pada saat pasang masuk dalam kategori sedang berkisar 0,99-1,6. Indeks keseragaman berkisar 0,78 - 0,91 masuk dalam kategori stabil. Indeks dominasi berkisar antara 0,22 - 0,41, dengan nilai tersebut maka keseluruhan stasiun penelitian masuk ke dalam katagori tidak terdapat dominasi. Nilai indeks keanekaragaman pada saat surut masuk dalam katagori sedang berkisar 0,91-1,41. Indeks keseragaman berkisar 0,660,91 masuk dalam kategori stabil. Indeks dominasi berkisar antara 0,32-0,45 dengan nilai tersebut maka dapat dikatagorikan sedang.

\section{UCAPAN TERIMA KASIH}

Penulis mengucapkan terima kasih kepada, Ir. Siti Rudyanti M.Si dan Oktavianto Eko Jati, S.Pi.,M.Si selaku dosen penguji yang telah memberikan masukan, serta arahan dalam penulisan jurnal ini 


\section{DAFTAR PUSTAKA}

Amarullah, M.H. 2008. Hidro-Biologi Larva Ikan dalam Proses Rekruitmen,. Jurnal Hidrosfir indonesia., 3(2):75-80 hlm

Basmi, J. 2000. Planktonologi : Plankton sebagai Indikator Kualitas air Bogor. Fakultas Prikanan dan Ilmu Kelautan. Institut Pertanian Bogor.

Dahuri, R., J. Rais., S.P. Ginting dan M.J. Sitepu. 2001. Pengelolaan Sumber Daya Wilayah Pesisir dan Lautan Secara Terpadu. Pradnya Paramita. Bogor

Hadi, S. 1982. Metodelogi Research. Percetakan Universitas Gadjah Mada. Jogjakarta

Nazir, M. 1988. Metode Penelitian. Ghalia Indonesia. Jakarta

Nomura, M. And T, Yamazaki.1997.Fishing Techniques 1. Japan Internationalcooperation Agency, Tokyo

Rahmadian, D.R. 2016. The Relationship between Larval Fish Abundance with Density of Mangrove in Delta Wulan, Demak District. Diponegoro Journal Of Maquares. 5(4): 182-189

Riniatsih, Ita. 2016. "Struktur Komunitas Larva Ikan pada Ekosistem Padang Lamun di Perairan Jepara”. Jurnal Kelautan Tropis. 19(1): $21-28$

Ruswanda, N. V. 2015. Community Structure of Fish Larvae in the Mangrove Ecosystem with Different Vegetation Age in Timbulsloko Village, Demak.. Diponegoro Journal Of Maquares. 4(4): 164 -173

Wizurai, P., S. Redjeki, dan T. S. Hartati. 2012. Studi Kelimpahan juvenil Ikan Pada Ekosistem Padang Lamun di Perairan Karimun Jawa,Kabupaten Jepara, Journal of Marine Research. 1(2): 27-34 